\title{
Effect of Chlorinated Solvents on Some Mechanical Properties of Polyester Fibre.
}

\author{
A.V. Popoola, A.O. Adetuyi and G.O. Oyeleke \\ Chemistry Department, Federal University of Technology, P.M.B. 704, Akure, Ondo State, Nigeria.
}

\begin{abstract}
Purified polyester commonly referred to as polyethylene terephthalate (PET) fibres were treated in four chlorinated solvents: perchloroethylene (PCE), trichloroethylene (TCE), 1,1-dichloroethylene (1,1-DCE) and tetrachloromethane (TCM) at room temperature for various time intervals of 30,60,150,300,450,600, 750, 900 and 1800 seconds to induce structural modifications of the PET fibre. The effects of these treatments in a relaxed condition on the tensile properties of the treated polyethylene terephthalate (PET) fibres for modulus $(\mathrm{MPa})$, tenacity $(\mathrm{MPa})$ and extension at break $(\mathrm{mm})$ were determined. A fall in the initial (Young's) modulus of all the treated fibres compared to the control ones was noticed, this may be due to the reduction in stiffness of the phenyl residue on the terephthalate group. The increase in the tenacity and extension at break of the treated fibres compared to the control ones could be linked to the stability conferred on them by the solvent treatments and the convolution occurring from chain folds in the treated fibres. Tetrachloromethane (TCM) was found to give the highest stable equilibrium tenacity and extension at break values within the first 600 secs of the treatments while these two quantities continue to vary with increase in time of treatment for the other three solvents. The stability of these two quantities in TCM treated fibres at shorter treatment time is a useful indication of textile materials that would not be deformed easily during processing and dry cleaning operations.
\end{abstract}

Keywords: Polyester, chlorinated, modifications, tenacity, modulus, extension at break, stability.

\section{Introduction}

Polyester is a category of polymer that contains ester functional groups in their chains. They are commonly referred to as polyethylene terephthalate (PET). In 1996, 24.1 million metric tons of manmade fibres were produced worldwide and the main volume gain took place in production of polyethylene terephthalate fibres [1].

PET is a condensation polymer and it is industrially produced by either reacting terephthalic acid or dimethyl terephthalate with ethylene glycol [2].

PET is the commonest linear polymer produced and it accounts for the majority of the polyester applied in industry today [3]. One of the distinguishing properties of PET is linked to the benzene rings in the polymer chain, this aromatic character leads to chain stiffness that prevents the deformation of disordered regions that results in weak Vander waals interaction forces between the chains and makes the PET difficult to be crystallized. The usual high melting point of PET is attributable to the ester linkages within the chain.

It is well known that the mechanical properties of PET fibres, yarns and fabrics are very significant in determining fibre properties and their decrease can influence the behaviour of textile materials [4]. Desirable tensile properties for textile can be produced by structural modifications that may be brought about by processes involving either heat or liquid treatments [5]. As the degree of fibre stretch is expected to increase (yielding high crystallinity and molecular orientation) after treatment, so are the properties such as tensile strength and initial (Young's) modulus. Methods to improve the surface characteristics of polyester fibre have been investigated by several workers $[6,7,8]$.

The aims of this research work are to treat polyester fibre in four selected chlorinated solvents at room temperature and to determine whether the tensile properties of the treated fibres would be enhanced or otherwise.

\section{Methodology}

Polyester fibre of about 50mg was weighed and treated in relaxed condition inside a $100 \mathrm{ml}$ conical flask with each of the chlorinated solvents at room temperature for $30,60,150,300,450,600,750,900$ and 1800 seconds to induce crystal morphology. The pretreated fibres were blotted between two filter papers, pressed under a load of $200 \mathrm{~g}$ to remove unabsorbed adhering surface solvents, air- dried at room temperature and kept in a vacuum dessicator prior to further analysis.

All solvent treated and control samples were conditioned at $65 \%$ relative humidity at $27^{\circ} \mathrm{C}$ for $36 \mathrm{~h}$ prior to determination of mechanical properties. The mechanical properties of the PET filaments were measured on the Uster Tensorapid (3. V7. 0. Model) tensile strength testing (Instron) machine at a constant rate of $100 \% / \mathrm{min}$ and a gauge length of $5.0 \mathrm{~cm}$ in all cases. The tensile strength testing machine was coupled to a microcomputer 
where initial (Young's) modulus (MPa), tenacity (MPa) and extension at break (mm) were computed for each of the treated and the control fibres.

\section{Results and Discussion}

\subsection{Results}

Table 1: Tensile Properties of TCM Treated Fibre

\begin{tabular}{llcc}
\hline Treatment Time (sec) & Modulus (MPa) & Tenacity (MPa) & Extension at Break $(\mathrm{mm})$ \\
\hline 30 & 561.71 & 0.55 & 51.22 \\
300 & 422.70 & 0.48 & 53.32 \\
600 & 603.76 & 0.66 & 60.07 \\
1800 & 599.30 & 0.66 & 59.46 \\
Control sample & 715.11 & 0.47 & 50.12 \\
\hline
\end{tabular}

Table 2: Tensile Properties of 1,1 DCE Treated Fibre

\begin{tabular}{llcc}
\hline Treatment Time $(\mathrm{sec})$ & Modulus $(\mathrm{MPa})$ & Tenacity $(\mathrm{MPa})$ & Extension at Break $(\mathrm{mm})$ \\
\hline 30 & 555.75 & 0.96 & 66.22 \\
300 & 436.18 & 0.66 & 58.68 \\
600 & 559.21 & 0.76 & 62.46 \\
1800 & 327.60 & 0.48 & 50.72 \\
Control sample & 715.11 & 0.47 & 50.12 \\
\hline
\end{tabular}

Table 3: Tensile Properties of PCE Treated Fibre

\begin{tabular}{cccc}
\hline Treatment Time $(\mathrm{sec})$ & Modulus $(\mathrm{MPa})$ & Tenacity $(\mathrm{MPa})$ & Extension at Break $(\mathrm{mm})$ \\
\hline 30 & 395.09 & 0.68 & 62.05 \\
300 & 539.93 & 0.78 & 57.72 \\
600 & 621.09 & 0.87 & 54.28 \\
1800 & 405.58 & 0.66 & 52.82 \\
Control sample & 715.11 & 0.47 & 50.12 \\
\hline \multicolumn{5}{c}{ Table 4: Tensile Properties of TCE Treated Fibre } \\
\hline Treatment Time $(\mathrm{sec})$ & Modulus $(\mathrm{MPa})$ & Tenacity (MPa) & Extension at Break (mm) \\
\hline 30 & 195.99 & 0.63 & 61.83 \\
300 & 387.15 & 0.60 & 56.48 \\
600 & 364.76 & 0.44 & 49.13 \\
1800 & 446.10 & 0.44 & 48.81 \\
Control sample & 715.11 & 0.47 & 50.12 \\
\hline
\end{tabular}

\subsection{Discussion}

Mechanical properties such as modulus, tenacity and extension at break are very important determinants in fabric processibility and therefore good tensile properties are needed for useful performance of the textile materials both in processing and in use. The required tensile properties can be produced by structural modifications that may be brought about either by heat or solvent treatments.

The results for the modulus, tenacity and extension at break for 1,1-DCE, PCE, TCE, TCM and the control fibres are shown each on tables 1-4 above.

\subsubsection{Extension at Break}

From the tables, increase in the extension at break of the solvent treated fibres compared to the control sample was noticed which could be explained in terms of the changes in the morphology that accompanied the solvent treatments. Changes observed in the structure of the treated fibres are similar to convolution from chain folds that are expected to extend relatively more than the control sample where such chain folds are not found. Similar increase in extension at break value has been reported by Ribnick et al., [9] 
Effect of Chlorinated Solvents on Some Mechanical Properties of Polyester Fibre.

Table 5: Solubility parameters of the four Chlorinated Solvents.

\begin{tabular}{ll}
\hline Solvents & solubility parameter \\
\hline 1,1-DCE & 9.76 \\
PCE & 9.30 \\
TCE & 9.28 \\
TCM & 8.65 \\
PET & 10.7
\end{tabular}

The influence of solubility parameter (from table 5) showing the interacting efficiency of each of the solvents on the polymer could be seen here with the average extension at break values for the solvent treated fibres following the increase in solubility parameter value of each of the solvent used in treating the fibre as shown here: 1,1-DCE > PCE > TCE > TCM.

The decrease in the quantity with increase in treatment time as observed with PCE and 1,1- DCE treated fibres did not show any direct correlation in the TCE and TCM treated fibres. The implication here is that this process of fibre extension is manifold which is controlled by the configuration of chain molecules, its energy content and the number of chemical bonds that hold them together in the amorphous regions of the fibre. The chain molecules in the fibre are held together by lateral forces such as covalent bonds, hydrogen bonds and Vander waals forces [10]. The flexibility of the chain molecules depend upon the holding power of these lateral forces to render flexibility to the chain molecules, thus resulting in higher extension values obtained compared to the control fibres.

\subsubsection{Tenacity}

From the results obtained in tables 1-4, the treated fibres have higher values than the control fibre. This is as a result of greater stability conferred by the solvents on the treated fibres. The increase in the strength and stability of the treated materials can be ascribed to the improvements in the structural order of the polymer matrix and generation of more number of crystallites leading to improvement in the resistance power to deform the materials with higher inter chain bond [11]. The results obtained here are similar to available reports available on the effects of solvent pretreatments on polymer wherein the solvents do not penetrate the compact crystalline region in the polymer and therefore do not adversely affect the strength of the materials [10].

\subsubsection{Initial (Young's) Modulus}

The modulus of a fibre measures its resistance to initial deformation. The moduli of the solvent treated fibres showed a fall from that of the control fibres. The decrease is an indication of the reduction in stiffness imparted by the phenyl residue of the terephthalate group [12], this may be due to the fact that small solvent molecule can usually diffuse through the crystalline domain, hence barrier properties and solvent resistance decrease.

The fall in the values of initial modulus of the treated samples are due to the effects of residual liquid trapped in the crystalline domain behaving as a plasticizer that induces segmental mobility (or increase mobility) in the amorphous regions.

The observations above were similar to those reported by Barella et al., [13], Rajendran and Mishra, [14] and Pal et al., [15].

\subsubsection{Tensile Properties and Stability of the Treated Fibre}

For useful performance of textile materials, good and stable tensile properties are considered desirable. The treated fibres showed higher tensile properties in terms of tenacity and extension at break than the control ones as explained earlier. From the results, TCM treated fibre was the only one among the four solvents that gave the highest average equilibrium values of $0.66 \mathrm{MPa}$ and $60.00 \mathrm{~mm}$ within 600 seconds treatment time for tenacity and extension at break. The other three solvents; TCE, PCE and 1,1-DCE did not show equilibrium tendencies as their values continued to vary throughout the treatment time. High tenacity value has been associated with stable delivery behaviour and high fabric strength, which are always considered in determining fibre properties [16]. Fibre tenacity should not be viewed in isolation as its extension at break is also important. Only the product of fibre tenacity and extension at break enable meaningful statements to be made regarding the further processing behaviour of the fibres. 


\section{Conclusion}

TCM as a solvent, imparted better equilibrium stability in terms of tenacity and extension at break within the time lag used in this research work compared to the other three chlorinated solvents; it is therefore considered the best in terms of stable tensile properties that are required to enhance better processing of the textile materials.

\section{Acknowledgement}

The assistance of Dr Johnson Oluwagbenga (South Africa), Mr. Abe Taiwo (FUT, Akure) and Tayo (EMDI, Akure) are gratefully acknowledged.

\section{References}

[1] Froehlich, F.W., Restructuring Innovation. See Akzo Nobel Through Difficult Business Environment. International Fibre Journal (12) (1997): 3

[2] Cook, J.G., Handbook of Textile Fibres. $4^{\text {th }}$ ed. (1968) Pp. 358-361.

[3] Allen, N.S., Edge, M., Mohammadian, M., Jones, K., Physicochemical Aspects of the Environmental Degradation of Poly (ethylene terephthalate). Polym. Degrad. Stab., 43(2) (1994): 229-237.

[4] Djordjevic, D.M., Petronijevic, Z.B. and Cvetkovic, D.M., Polyester Fabric Modification by some Lipases. CI\&CEQ II (4) (2005): 183-188.

[5] Popoola, A.V. and Peters, R.H., Mechanical Properties of Structurally Modified Polyethylene Terephthalate Fibres. Journal of Engineering Applications 1 (1) (1998): 20-22.

[6] Ugbolue, S.C.O. and Popoola, A.V., Studies on Solvent Induced Structural Modifications of Poly (ethylene terephthalate) Filaments. Acta Polymerica. 40. Nr 7 (1989): 475-479.

[7] Muralidharan, B., Mathanmohan, T. and Ethiraj, J., J. Appl. Polym. Sci. 91 (6) (2004): 3871.

[8] Samanta, A.K., Chattophathyay, D.P., Konar, A. and Sharma, D.N., Indian J. Fibre Tex. Res., 28 (2003): 76-85.

[9] Ribnick, A.S., Weigmann, H.D. and Rebenfeld, L. Text. Res. J. 42 (1972): 720.

[10] Rajendran, S., Ramasamy, S.S. and Mishra, S.P., Studies on Dyeing and Structural Behaviour of Polyester Yarns. Journal of Applied Polymer Science. 62 (7) (1996): 989-1001.

[11] Muralidharan, B. and Laya, S. (2011). A New Approach to Dyeing of 80:20 Polyester/ Cotton Blended Fabric using Disperse and Reactive Dyes. ISRN Material Science. Vol.. 2011 (12 pages)

[12] Bal, S. and Behera, R.C., Structural Investigation of Chemical Treated Polyester fibres Using SAXS and other techniques. Journal of Mineral and Materials Characterization and Engineering. Vol. 5, No 2 (2006): 179-198.

[13] Barella, A., Alvarez vega, P.A. and Castro, L., Milliand Textilber, 71 (1990): 947.

[14] Rajendran, S. and Mishra, S.P. (2007). Chemical, Structural and Thermal Changes in PET Caused by solvent Induced Polymer Crystallization. Polymer and Polymer Composites. 15(2) (2007): 103-110.

[15] Pal, S.K., Gandhi, R.S and Kothari, V.K., Indian J. Fibre and Text. Res., 22 (1991): 146.

[16] Behera, B.K. and Mishra, R., Artificial Neural Network based Prediction of Aesthetic and Functional Properties of Worsted Suiting Fabrics. Int. Journal of Clothing. Vol. 19, Issue 5 (2007): 259-276. 